\title{
Numerical Modeling of Sediment Transport and Its Effect on Algal Biomass Distribution in Lake Pontchartrain Due to Flood Release from Bonnet Carré Spillway
}

\author{
Xiaobo Chao, Yafei Jia, A. K. M. Azad Hossain \\ National Center for Computational Hydroscience and Engineering, University of Mississippi, Oxford, USA \\ Email:chao@ncche.olemiss.edu
}

How to cite this paper: Chao, X.B., Jia, Y.F. and Azad Hossain, A.K.M. (2016) Numerical Modeling of Sediment Transport and Its Effect on Algal Biomass Distribution in Lake Pontchartrain Due to Flood Release from Bonnet Carré Spillway. Journal of Geoscience and Environment Protection, 4, 6479.

http://dx.doi.org/10.4236/gep.2016.49006

Received: July 27, 2016

Accepted: September 18, 2016

Published: September 21, 2016

Copyright $\odot 2016$ by authors and Scientific Research Publishing Inc. This work is licensed under the Creative Commons Attribution International License (CC BY 4.0).

http://creativecommons.org/licenses/by/4.0/ (c) (i) Open Access

\begin{abstract}
In order to protect the city of New Orleans from the Mississippi River flooding, the Bonnet Carré Spillway (BCS) was constructed from 1929 to 1936 to divert flood water from the river into Lake Pontchartrain and then into the Gulf of Mexico. During the BCS opening for flood release, large amounts of freshwater, nutrients, sediment, etc. were discharged into Lake Pontchartrain, and caused a lot of environmental problems. To evaluate the environmental impacts of the flood water on lake ecosystems, a two-dimensional numerical model was developed based on CCHE2D and applied to simulate the flow circulation, sediment transport and algal biomass distribution in Lake Pontchartrain. The effect of sediment concentration on the growth of algae was considered in the model. The numerical model was calibrated using field measured data provided by USGS, and then it was validated by the BCS Opening Event in 1997. The simulated results were generally in good agreement with filed data and satellite imagery. The field observation and numerical model show that during the spillway opening for flood release, the sediment concentration is very high, which greatly restricts the growth of algae, so there is no algal bloom observed in the lake. After the closure of BCS, the sediment concentration in the lake reduces gradually, and the nutrient concentration of the lake is still high. Under these conditions, numerical results and satellite imagery showed that the chlorophyll concentration was high and algal bloom might occur.
\end{abstract}

\section{Keywords}

2D Numerical Model, Flow Circulation, Sediment Transport, Algal Bloom, Bonnet Carré Spillway, Lake Pontchartrain 


\section{Introduction}

Lake Pontchartrain located in southeastern Louisiana, is the second largest saltwater lake in the United States. It connects to the Gulf of Mexico via Rigolets strait to Lake Borgnes via Chef Menteur Pass, and to Lake Maurepas via Pass Manchac. These lakes form one of the largest estuaries in the Gulf Coast region (Figure 1).

The Lake Pontchartrain Basin is Louisiana's premier urban estuary and nearly one-third of the state population live within this area. Over the past few decades, rapid growth and development within the Lake Basin have resulted in significant degradation of lake water quality (Penland et al., 2002) [1]. In addition, the lake is also used as a flood diversion area for protecting the city of New Orleans. When the water surface level in the Mississippi River near New Orleans approaches the flood stage of 5.18 meters, Bonnet Carré Spillway (BCS) will be opened to divert water from the river into Lake Pontchartrain and then into the Gulf of Mexico. The BCS opening event will significantly affect the distributions of salinity, temperature, nutrients and suspended sediment in the lake, and as a result, cause many environmental problems for the lake. It was observed that algal bloom occurred due to the flood release to the lake.

Lake Pontchartrain is a large and shallow lake, and the vertical stratification of the lake is not significant. In this study, a 2D depth-averaged numerical model was developed

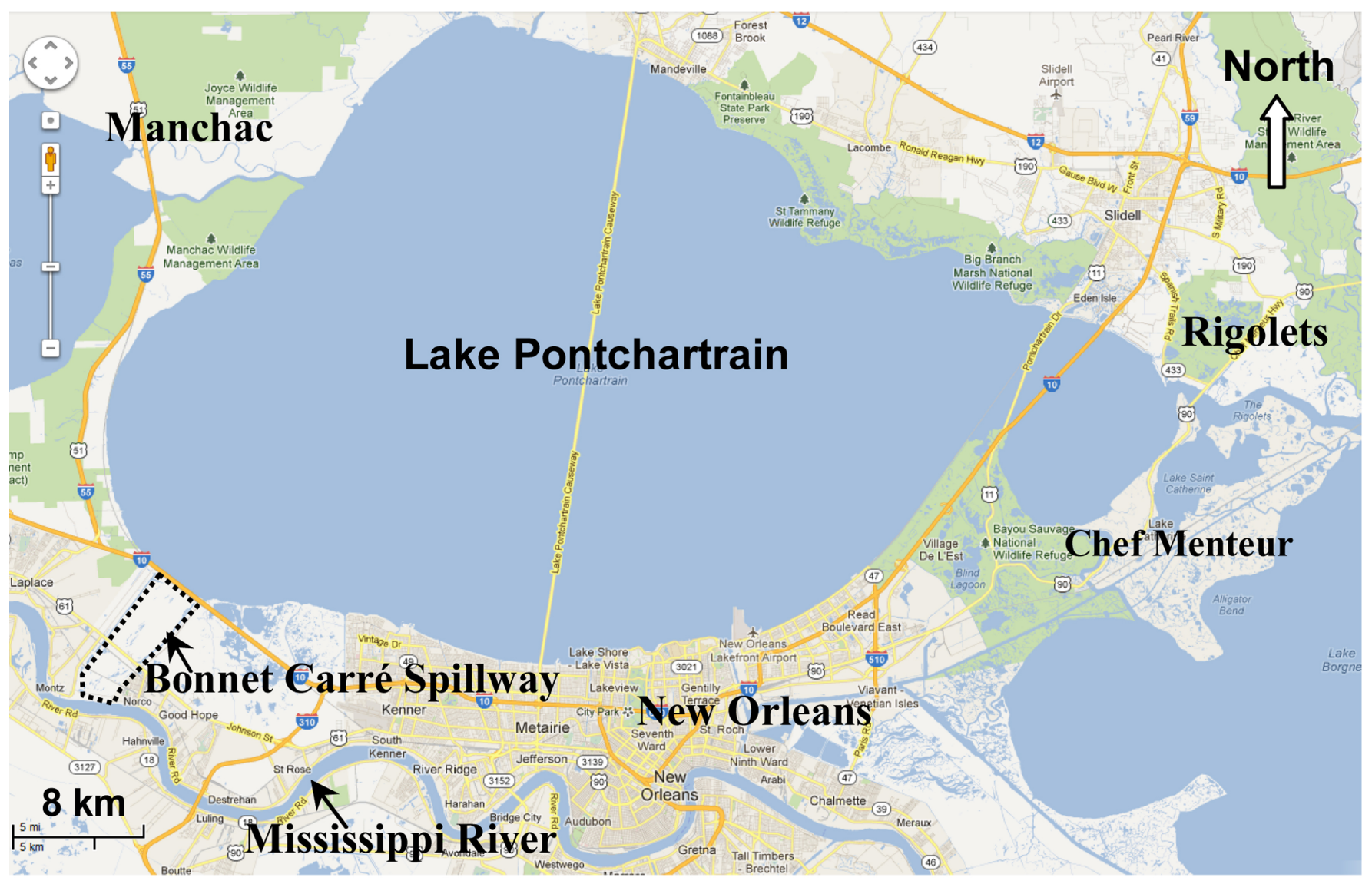

Figure 1. Lake Pontchartrain. 
based on the CCHE2D hydrodynamic model (Jia et al., 2013) [2] to simulate the flow circulation, sediment transport as well as algae biomass distribution in the lake due to the flood release from BCS. The water movements within the lake are induced by the spillway discharge, wind and tide. The simulated flow circulations were calibrated using field measured data provided by USGS, and the sediment concentration and algal biomass were validated using satellite imagery.

\section{Model Description}

CCHE2D is a depth-averaged 2D hydrodynamic and sediment transport model that can be used to simulate unsteady free surface turbulent flow and sediment concentration (Jia et al., 2013) [2]. It was developed by the National Center for Computational Hydroscience and Engineering, the University of Mississippi. A numerical module was developed and decoupled with CCHE2D to simulate the algal biomass distribution in the water.

\subsection{Governing Equations for Flow Field and Sediment Transport}

The free surface elevation of the flow is calculated by the continuity equation:

$$
\frac{\partial h}{\partial t}+\frac{\partial u h}{\partial x}+\frac{\partial v h}{\partial y}=0
$$

The momentum equations for the depth-integrated two-dimensional model in the Cartesian coordinate system are:

$$
\begin{aligned}
& \frac{\partial u}{\partial t}+u \frac{\partial u}{\partial x}+v \frac{\partial u}{\partial y}=-g \frac{\partial \eta}{\partial x}+\frac{1}{h}\left(\frac{\partial h \tau_{x x}}{\partial x}+\frac{\partial h \tau_{x y}}{\partial y}\right)+\frac{\tau_{s x}-\tau_{b x}}{\rho h}+f_{\text {Cor }} v \\
& \frac{\partial v}{\partial t}+u \frac{\partial v}{\partial x}+v \frac{\partial v}{\partial y}=-g \frac{\partial \eta}{\partial y}+\frac{1}{h}\left(\frac{\partial h \tau_{y x}}{\partial x}+\frac{\partial h \tau_{y y}}{\partial y}\right)+\frac{\tau_{s y}-\tau_{b y}}{\rho h}-f_{\text {Cor }} u
\end{aligned}
$$

where $u$ and $v$ are the depth-integrated velocity components in $x$ and $y$ directions, respectively; $t$ is the time; $g$ is the gravitational acceleration; $\eta$ is the water surface elevation; $\rho$ is the density of water; $h$ is the local water depth; $f_{C o r}$ is the Coriolis parameter; $\tau_{x x} \tau_{x y} \tau_{y x}$ and $\tau_{y y}$ are depth integrated Reynolds stresses; $\tau_{s x} \tau_{s y}$ and $\tau_{b x} \tau_{b y}$ are surface and bed shear stresses in $x$ and $y$ directions, respectively.

The turbulence Reynolds stresses in Equations (2) and (3) are approximated according to the Bousinesq's assumption that are related to the main rate of the strains of the depth-averaged flow field and an eddy viscosity coefficient $v_{t}$ which is computed using the Smagorinsky scheme (Smagorinsky, 1993) [3]:

$$
v_{t}=\alpha \Delta x \Delta y\left[\left(\frac{\partial u}{\partial x}\right)^{2}+\frac{1}{2}\left(\frac{\partial v}{\partial x}+\frac{\partial u}{\partial y}\right)^{2}+\left(\frac{\partial v}{\partial y}\right)^{2}\right]^{1 / 2}
$$

The parameter $\alpha$ ranges from 0.01 to 0.5 . In this study, it was taken as 0.1 .

In CCHE2D model, three approaches are adopted to simulate non-uniform sediment transport. One is the bed load transport, which is to simulate the bed load only without 
considering the diffusion of suspended load. The second approach is the suspended load transport, which simulates suspended load and treats bed-material load as suspended load. The third approach is to simulate bed load and suspended load separately (Jia and Wang, 1999 [4], Jia et al., 2002 [5], Wu, 2008 [6]).

In this study, CCHE2D was used to simulate sediment transport in Lake Pontchartrain during the BCS opening for flood release. In this period, sediment transport in the lake is primarily dominated by suspended sediment. So the second sediment transport approach, suspended load, was used for this study, and the non-uniform suspended sediment (SS) transport equation can be written as:

$$
\frac{\partial c_{k}}{\partial t}+u \frac{\partial c_{k}}{\partial x}+v \frac{\partial c_{k}}{\partial y}=\frac{\partial}{\partial x}\left(D_{c x} \frac{\partial c_{k}}{\partial x}\right)+\frac{\partial}{\partial y}\left(D_{c y} \frac{\partial c_{k}}{\partial y}\right)+S_{c k}
$$

where $c_{k}$ is the depth-averaged concentration of the $k$ th size class of SS; $D_{c x}$ and $D_{c y}$ are the mixing coefficients of SS in $x$ and $y$ directions, respectively; $S_{c k}$ is the source term and can be calculated by:

$$
S_{c k}=-\frac{\alpha_{t} \omega_{s k}}{h}\left(c_{k}-c_{t^{*} k}\right)
$$

where $c_{t^{*} k}$ is the equilibrium sediment concentration of the $k$ th size class of suspended load; $\omega_{s k}$ is the settling velocity of the $k$ th size class; $\alpha_{t}$ is the adaptation coefficient of suspended load, and it can be estimated using the formula proposed by $\mathrm{Wu}$ (2008) [6].

In natural lakes, the wind shear stresses $\left(\tau_{s x}\right.$ and $\left.\tau_{s y}\right)$ at the free surface are expressed by

$$
\begin{gathered}
\tau_{\text {sx }}=\rho_{a} C_{d} U_{\text {wind }} \sqrt{U_{\text {wind }}^{2}+V_{\text {wind }}^{2}} \\
\tau_{\text {sy }}=\rho_{a} C_{d} V_{\text {wind }} \sqrt{U_{\text {wind }}^{2}+V_{\text {wind }}^{2}}
\end{gathered}
$$

where $\rho_{a}$ is the air density; $U_{\text {wind }}$ and $V_{\text {wind }}$ are the wind velocity components at $10 \mathrm{~m}$ elevation in $x$ and $y$ directions, respectively. Although the drag coefficient $C_{d}$ may vary with wind speed (Koutitas and O'Connor, 1980 [7]; Jin et al., 2000 [8]), for simplicity, many researchers assumed the drag coefficient was a constant on the order of $10^{-3}$ (Huang and Spaulding, 1995 [9], Rueda and Schladow, 2003 [10], Chao et al., 2004 [11]). In this study, $C_{d}$ was taken as $1.0 \times 10^{-3}$.

\subsection{Governing Equations for Algae Biomass}

Phytoplankton (free-floating algae) and aquatic plants are the two major primary producers in surface water. Algae play a central role in the eutrophication process. Algal concentration is typically expressed in biomass as carbon per unit volume, and in practice, total algal biomass is often represented by chlorophyll a. The relationship between chlorophyll a and algal biomass can be expressed as

$$
M=\alpha C_{c h l}
$$

in which $M$ is the algal biomass; $C_{C h l}$ is the concentration of chlorophyll a; $\alpha$ is the carbon to chlorophyll ratio. 
The transport equation of algal biomass can be written as

$$
\frac{\partial M}{\partial t}+\frac{\partial(u M)}{\partial x}+\frac{\partial(v M)}{\partial y}=\frac{\partial}{\partial x}\left(D_{m x} \frac{\partial M}{\partial x}\right)+\frac{\partial}{\partial y}\left(D_{m y} \frac{\partial M}{\partial y}\right)+S_{m}
$$

in which $D_{m x}, D_{m y}$ and $D_{m z}$ are the mixing coefficients of algae in $x$ and $y$ directions, respectively; $S_{m}$ is the effective source.

The effective source term for algal biomass $S_{m}$ in Equation (10) can be calculated by

$$
S_{m}=\left(G_{p}-D_{p}-P_{\text {set }}\right) M
$$

in which $G_{p}$ is the growth rate of algae $\left(\right.$ day $\left.^{-1}\right) ; D_{p}$ is the death rate of algae $\left(\right.$ day $\left.^{-1}\right)$; and $P_{\text {set }}$ is the effective algal settling rate $\left(\right.$ day $\left.^{-1}\right)$.

Algal bloom is a rapid increase or accumulation in the population of algae in an aquatic system. When conditions of nutrients, sunlight, and water temperature are favorable, algal bloom may occur. The algal growth rate is determined by the availability of nutrients, the intensity of light, and by the ambient temperature. The effects of each factor are considered to be multiplicative:

$$
G_{p}=P_{m x} f_{N} f_{I} f_{T}
$$

in which $P_{m x}$ is the maximum algal growth rate $\left(\right.$ day $\left.^{-1}\right)$; and $f_{N}, f_{I}$ and $f_{T}$ are the limitations due to nutrient availability, light intensity, and temperature, respectively.

The nutrient limitation factor $f_{N}$ is determined by the concentration of nitrogen and phosphorus. It is calculated based on Michaelis-Menten Equation and Liebig's law of the minimum (Cerco and Cole, 1995 [12]; Wool et al., 2001 [13]):

$$
f_{N}=\min \left(\frac{D I N}{D I N+K_{m N}}, \frac{D I P}{D I P+K_{m P}}\right)
$$

where DIN and DIP are the concentrations of dissolved inorganic nitrogen and dissolved inorganic phosphorus; $K_{m N}$ and $K_{m P}$ are the half-saturation constants for nitrogen and phosphorus uptake, respectively.

The light limitation factor $f_{I}$ is obtained by integrating the Steele equation over depth and time (Chapra, 1997 [14]):

$$
f_{I}=\frac{2.72 f_{d}}{K_{e} h}\left[\exp \left(-\frac{I_{0}}{I_{m}} \mathrm{e}^{-K_{e} h}\right)-\exp \left(-\frac{I_{0}}{I_{m}}\right)\right]
$$

in which $f_{d}$ is the fractional daylight; $I_{o}$ is the daily averaged light intensity at the water surface; $I_{m}$ is the saturation light intensity of algae. $K_{e}$ is the total light attenuation coefficient, and it is determined by the effects of water, chlorophyll and suspended sediment (SS), and can be expressed by (Chao et al., 2007, [15]):

$$
K_{e}=K_{0}+0.0088 C_{c h l}+0.054 C_{c h l}^{0.67}+0.0452 c
$$

where $K_{o}$ is the light attenuation by pure water; $C_{c h l}$ is the concentration of chlorophyll a and $c$ is the concentration of suspended sediment. The light attenuation coefficient $K_{e}$ is greatly affected by the high concentration of SS.

The temperature limitation factor $f_{T}$ is calculated using the following formula (Cerco 
and Cole, 1995 [12]):

$$
\begin{gathered}
f_{T}=\exp \left[-K T g_{1}\left(T-T_{m}\right)^{2}\right] \text { when } T \leq T_{m} \\
f_{T}=\exp \left[-K T g_{2}\left(T_{m}-T\right)^{2}\right] \text { when } T>T_{m}
\end{gathered}
$$

in which $T$ is the temperature $\left({ }^{\circ} \mathrm{C}\right) ; T_{m}$ is the optimal temperature for phytoplankton growth $\left({ }^{\circ} \mathrm{C}\right) ; \mathrm{KTg}_{1}$ and $K T g_{2}$ are coefficients representing the effects of temperature on growth below and above $T_{m}$, respectively.

Algae losses mainly include endogenous respiration, mortality and grazing by zooplankton. In this study, the zooplankton predation was not considered, and the algal death rate is given as follows:

$$
D_{p}=k_{p r} \theta_{p r}^{T-20}+k_{p d}
$$

where $k_{p r}$ and $k_{p d}$ are the rates of endogenous respiration and mortality, respectively $\left(\right.$ day $\left.^{-1}\right) ; \theta_{p r}$ is the temperature coefficient.

The effective algal settling rate $P_{\text {set }}$ in Equation (11) is given as:

$$
P_{s e t}=\frac{\omega_{s 4}}{h}
$$

where $\omega_{s 4}$ is the settling velocity of algae (m/day).

In this study, the decoupled approach was used to simulate the concentration of algal biomass. At each time step, the flow fields and sediment distribution were first obtained using the CCHE2D hydrodynamic model, and then the concentration of algal biomass was solved numerically using Equation (10).

\subsection{Numerical Solution}

CCHE2D model is a finite element model utilizing a special method based on the collocation approach called the efficient element method (Jia et al., 2013) [2]. This model is based on the 2D Reynolds-averaged Navier-Stokes equations. By applying the Boussinesq approximation, the turbulent stress can be simulated by the turbulent viscosity and time-averaged velocity. There are several turbulence closure schemes available within CCHE2D, including the parabolic eddy viscosity, mixing length, Smagorinsky scheme, $k$ - $\varepsilon$ and nonlinear $k$ - $\varepsilon$ models.

In the numerical model, the unsteady equations are solved using the time-marching scheme. The velocity correction method is applied to solve the dynamic pressure and enforce mass conservation. The system of the algebraic equations is solved using the Strongly Implicit Procedure (SIP). The flow fields and sediment transport are solved simultaneously. While the algae biomass module is decoupled with hydrodynamic model, and the concentration of algae biomass (or chlorophyll a) is simulated separately.

\section{Model Application to Lake Pontchartrain}

\subsection{Study Area}

Figure 2 shows the bathymetry of Lake Pontchartrain. It covers an area of 1630 square 


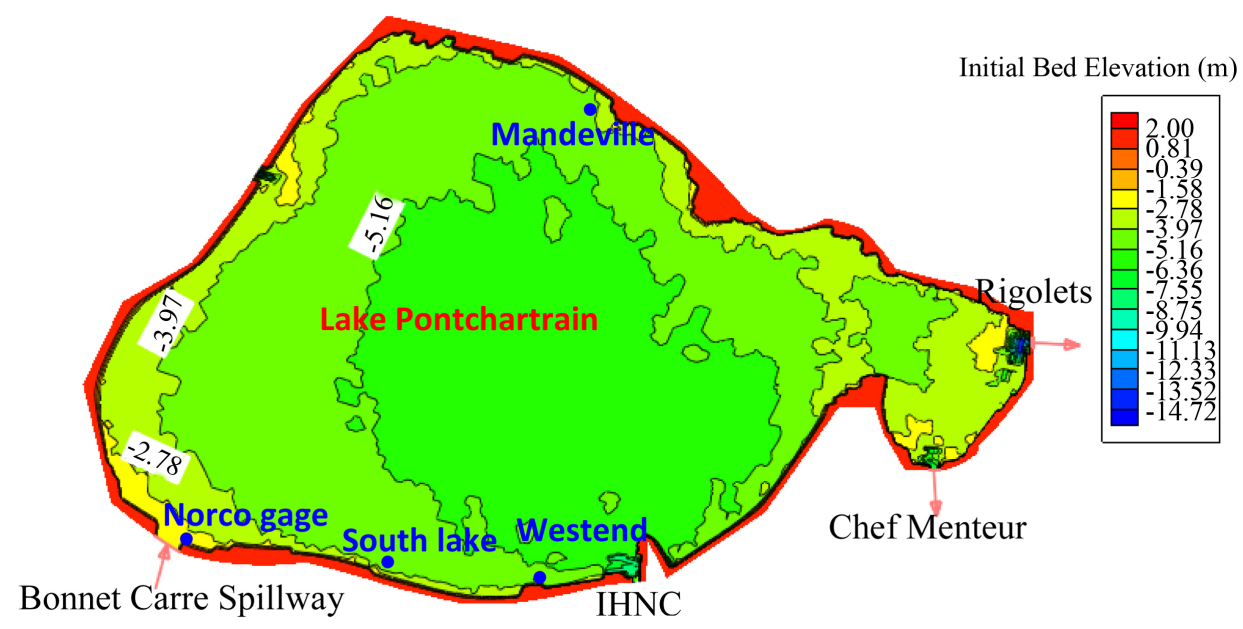

Figure 2. The bathymetry of Lake Pontchartrain.

$\mathrm{km}$ with a mean depth of 4 meters. It is an oval-shaped quasi-enclosed water body with the main east-west axis spanning $66 \mathrm{~km}$, while the shorter north-south axis is about 40 $\mathrm{km}$. Wind and tide are the major driving mechanisms of the lake circulations. The lake has a diurnal tide with a mean range of $11 \mathrm{~cm}$. Higher salinity waters from the Gulf of Mexico can enter the lake through two narrow tidal passes: the Rigolets and Chef Menteur. When Bonnet Carré Spillway (BCS) is opened for flood release, large amount of fresh water, sediment and contaminants will discharge into Lake Pontchartrain.

Lake Pontchartrain is a large and shallow lake, and the vertical stratification of the lake is not significant. A 2D depth-averaged model, CCHE2D was applied to simulate the flow field, sediment transport, and algal biomass distribution in the lake due to the flood release from BCS. Based on the bathymetric data, the computational domain was divided into a number of grids using the CCHE Mesh Generator (Zhang and Jia, 2009 [16]). The computational domain was represented by a $224 \times 141$ irregular structured mesh in the horizontal plane.

\subsection{Model Calibration}

The period from March 1-31, 1998, was selected for model calibration. At the three narrow passes: Rigolets, Chef Menteur, and IHNC, the measured water surface elevation obtained from USGS were set as tidal boundaries. The wind speeds and directions at the New Orleans International Airport obtained from the National Climatic Data Center, NOAA, were used for model simulation. For calibration runs, a few parameters, such as drag coefficient $C_{d}$, Manning's roughness coefficient, etc., were adjusted to obtain a reasonable reproduction of the field data provided by USGS. In this study, drag coefficient $C_{d}=0.001$ and Manning's roughness coefficient $=0.025$. Simulated water surface elevations and depth-averaged velocities were compared with the field measurements. Figure 3 shows the simulated and measured water surface elevations at the Mandeville Station. Figure 4 and Figure 5 show the simulated and measured depthaveraged velocities in $\mathrm{x}$ and $\mathrm{y}$ directions at the South Lake Site. In general, the 


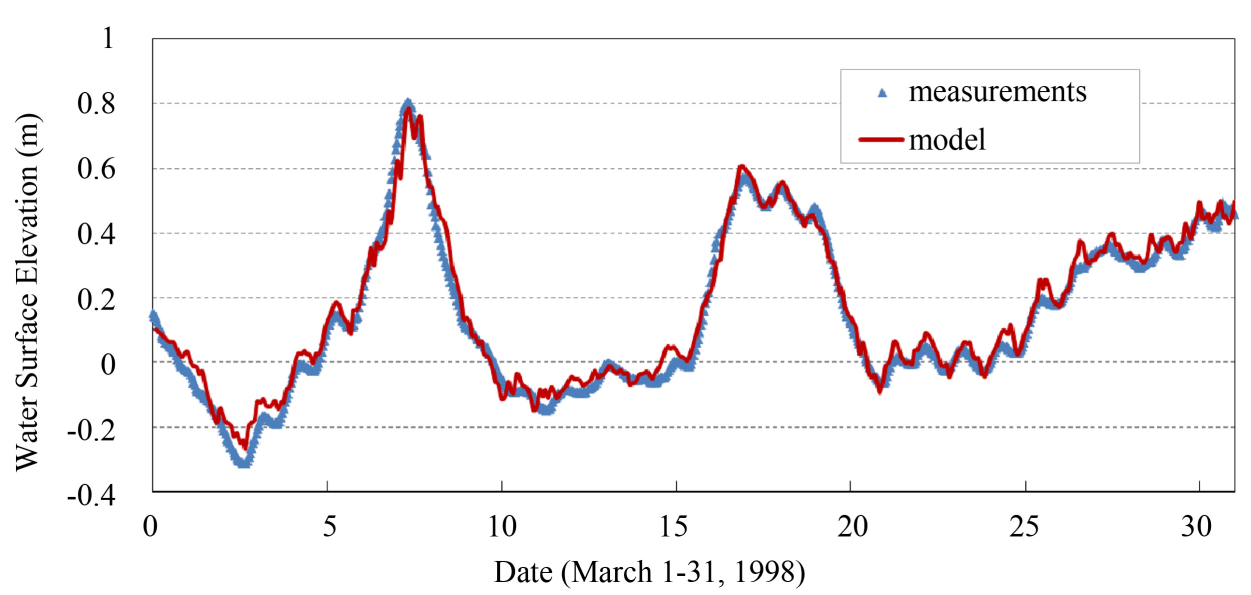

Figure 3. Simulated and measured water surface elevations at the Mandeville station.

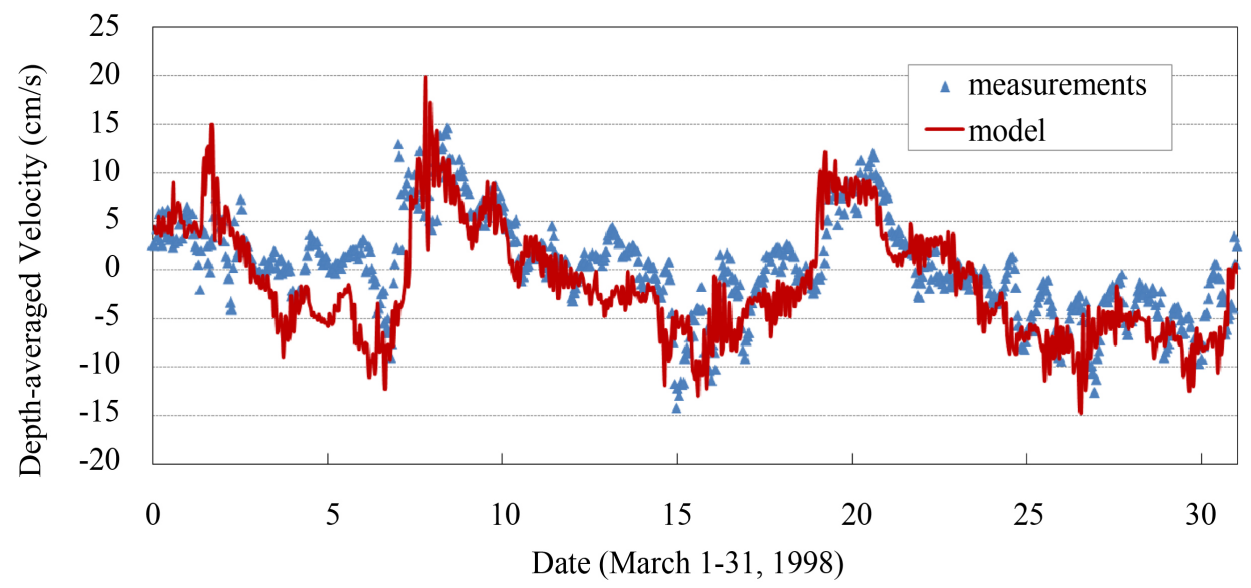

Figure 4. Simulated and measured velocities in west-east direction at the south lake site.

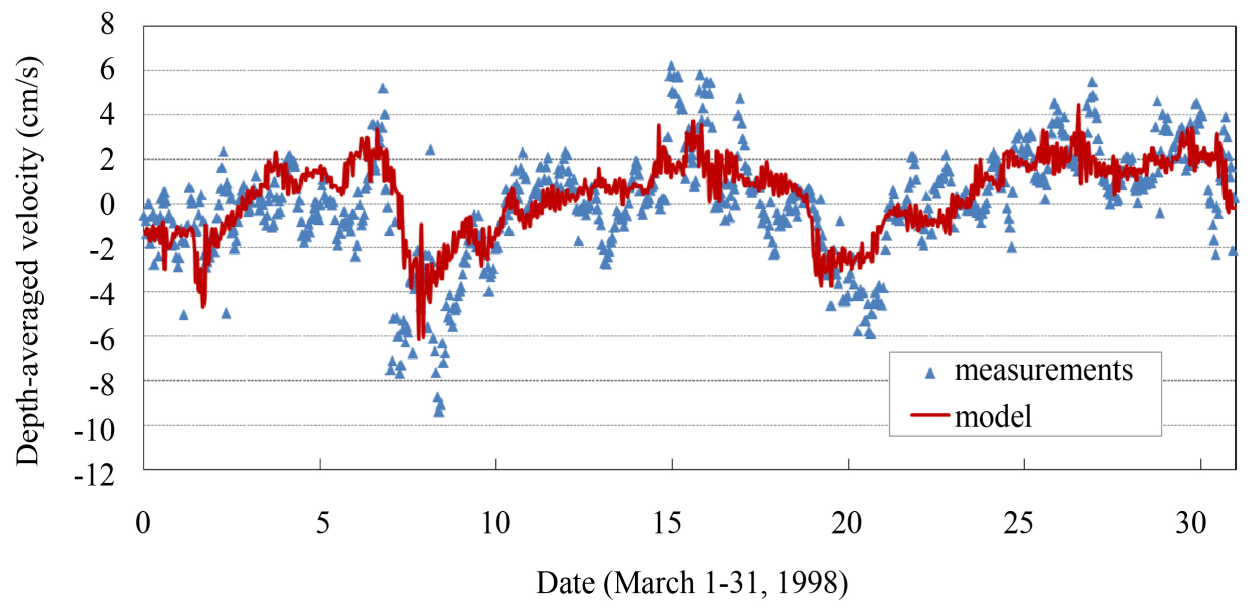

Figure 5. Simulated and measured velocities in south-north direction at the south lake site.

flow fields produced by the numerical model were in good agreement with field measurements. 


\subsection{Modeling the Flow and Sediment Transport during the BCS Opening for Flood Release}

In response to the high flood stage of the Mississippi River and to protect the city of New Orleans, the Bonnet Carré Spillway (BCS) was built between 1929 and 1936. The spillway diverts Mississippi River flood waters to the Gulf of Mexico via Lake Pontchartrain. The design capacity of the spillway is $7080 \mathrm{~m}^{3} / \mathrm{s}$. It was first operated in 1937 and ten times thereafter $(1945,1950,1973,1975,1979,1983,1997,2008,2011$, and 2016).

During the BCS opening, a large amount of fresh water and sediment discharged from the Mississippi River into Lake Pontchartrain and then into the Gulf of Mexico. The fresh water dominated the whole lake and the lake salinity reduced significantly. A lot of sediment deposited into the lake or was transported into the Gulf of Mexico. The contaminated sediment from Mississippi River could bring a lot of pollutants, such as nutrients, $\mathrm{Al}, \mathrm{Cu}, \mathrm{Cr}, \mathrm{Hg}, \mathrm{Pb}, \mathrm{Zn}$, etc., to the lake, and caused a lot of environmental problems (Penland et al., 2002) [1].

The calibrated model was applied to simulate the lake flow fields and sediment transport during the BCS opening between 3/17-4/18, 1997. In this period, the averaged discharge was about $4358 \mathrm{~m}^{3} / \mathrm{s}$, and the maximum flow discharge was about $6800 \mathrm{~m}^{3} / \mathrm{s}$. The spillway partial opening was completed on March 27. The US Army Corps of Engineers (USACE) began to close the spillway on April 2, and it was completely closed by April 18. During this period, the averaged suspended sediment concentration at the spillway gate was about $240 \mathrm{mg} / \mathrm{l}$. The flow hydrograph and sediment concentration were set as inlet boundary conditions at BCS. The water surface elevations at Rigolets and Chef Menteur Pass obtained from USGS were set as tidal boundaries. The wind speeds and directions at the New Orleans International Airport were used for model simulation.

Figure 6 shows the flow circulations in Lake Pontchartrain when the spillway opened

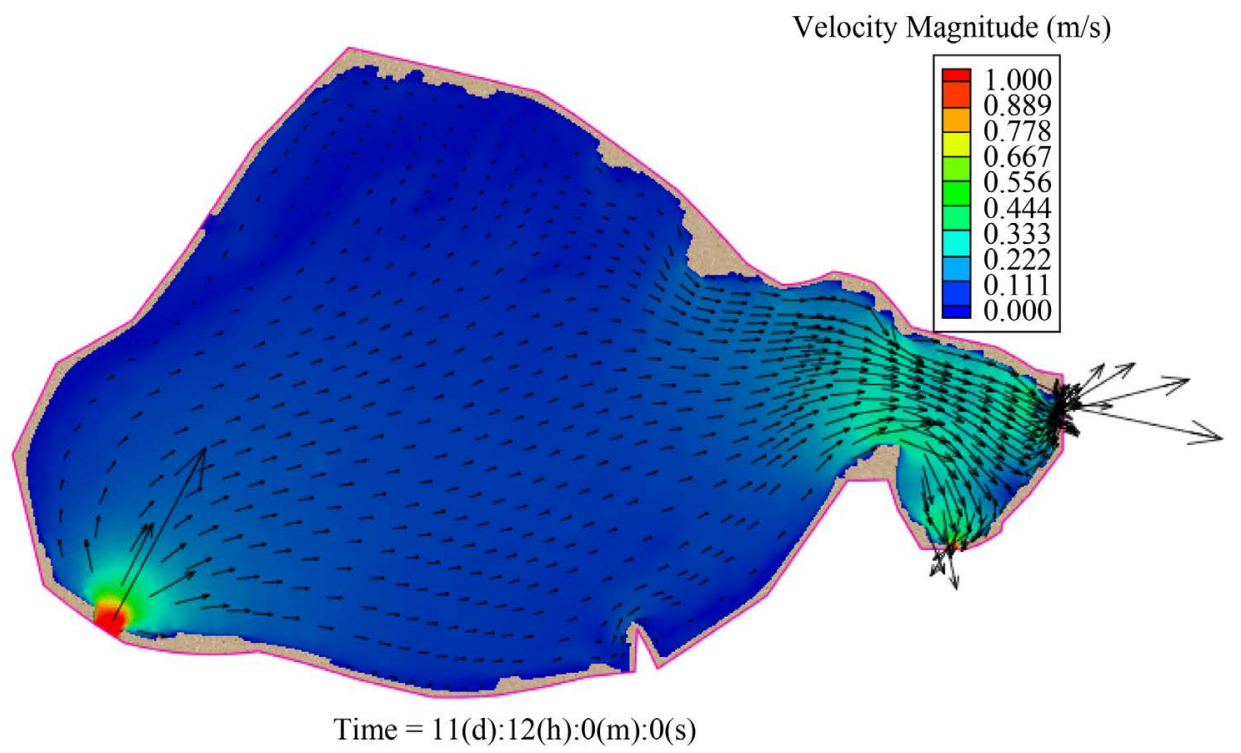

Figure 6. Shows the flow circulations in Lake Pontchartrain. 
completely. The flow discharge over the spillway dominated the lake hydrodynamics and caused the entire lake water to be moved eastward through Rigolets and Chef Menteur Pass into the Gulf of Mexico. The flow pattern was completely different from the one induced by tide and wind.

Figure 7 shows the comparisons of suspended sediment (SS) concentration obtained from numerical model and remote sensing imageries provided by NOAA. The simulated suspended sediment concentrations are generally in good agreement with satellite imageries. The numerical results and satellite imageries show that a large amount of sediment discharged into the lake, moved eastward along the south shore and gradually expanded northward, eventually affecting the entire lake after one month of diversion.

\subsection{Modeling Algae Biomass Distribution in Lake Pontchartrain Due to the BCS Flood Release}

The nutrient levels in the Mississippi River are much higher than those in Lake Pontchartrain. When the BCS is opened for flood release, the river water with high nutrient concentrations flows into the lake. As shown in Equation (12), the algal growth rate is depended on the nutrient levels, light intensity and water temperature. So the BCS opening event will affect the growth of algae. It was reported, in Lake Pontchartrain, the low ratio between dissolved inorganic nitrogen (DIN) and dissolved inorganic phosphorus (DIP) indicate that the nitrogen is the limiting nutrient for algae growth (Dortch et al., 1998 [17], McCorquodale et al., 2004 [18]).

In 1997, the BCS was opened from March 18 to April 17. It was observed that the
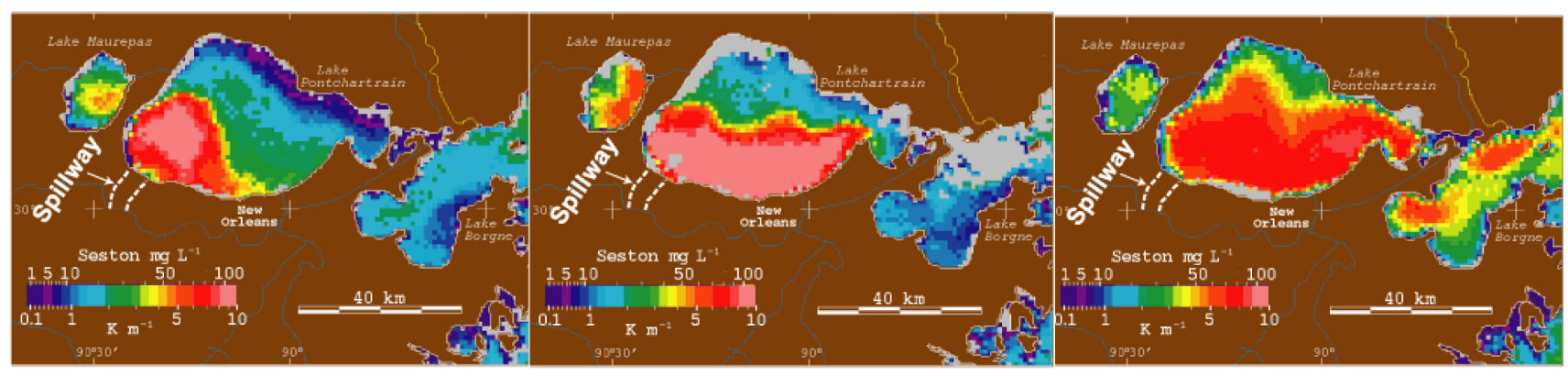

Remote sensing imageries

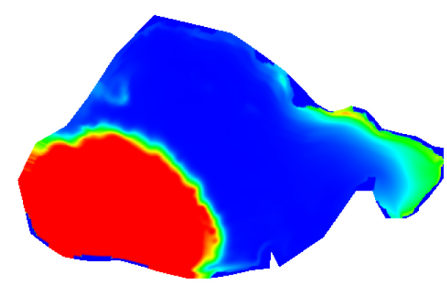

$3 / 24 / 97$

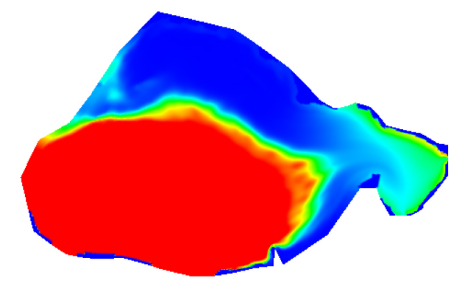

$3 / 26 / 97$

SS concentration $\left(\mathrm{kg} / \mathrm{m}^{3}\right)$

\section{Numerical model results}

Figure 7. Comparisons of simulated SS concentration and remote sensing imageries. 
DIN concentrations in the lake increased about 10 times, from normal $0.05 \mathrm{mg} / \mathrm{l}$ to 0.5 mg/l (Dortch et al., 1998 [17], McCorquodale et al., 2004 [18]). The higher nitrogen level would greatly increase the algae growth rate. The field observations showed that a visually obvious algal bloom became apparent over large parts of the lake by the end of May, and the peak bloom occurred in mid-June.

The developed model was applied to simulate the algae biomass distribution after the BCS opening event. The simulation period was selected from May 28 to July 2, 1997. In this period, wind and tide were the most important forces for flow circulations. After obtaining the wind data and water surface elevation in this period, the model was first applied to simulate the flow fields in Lake Pontchartrain. The initial chlorophyll concentration was estimated using satellite imagery (Figure 8). The nutrient levels were much higher than the saturated levels for algae growth. During this period, the concentration of suspended sediment was lower than $10 \mathrm{mg} / \mathrm{l}$ (McCorquodale et al., 2004) [18]. Based on the observed light intensity and water temperature data provided by USACE (Figure 9 and Figure 10), the model was used to simulate the algal biomass distribution. Since the algal biomass is often represented by chlorophyll concentration, the

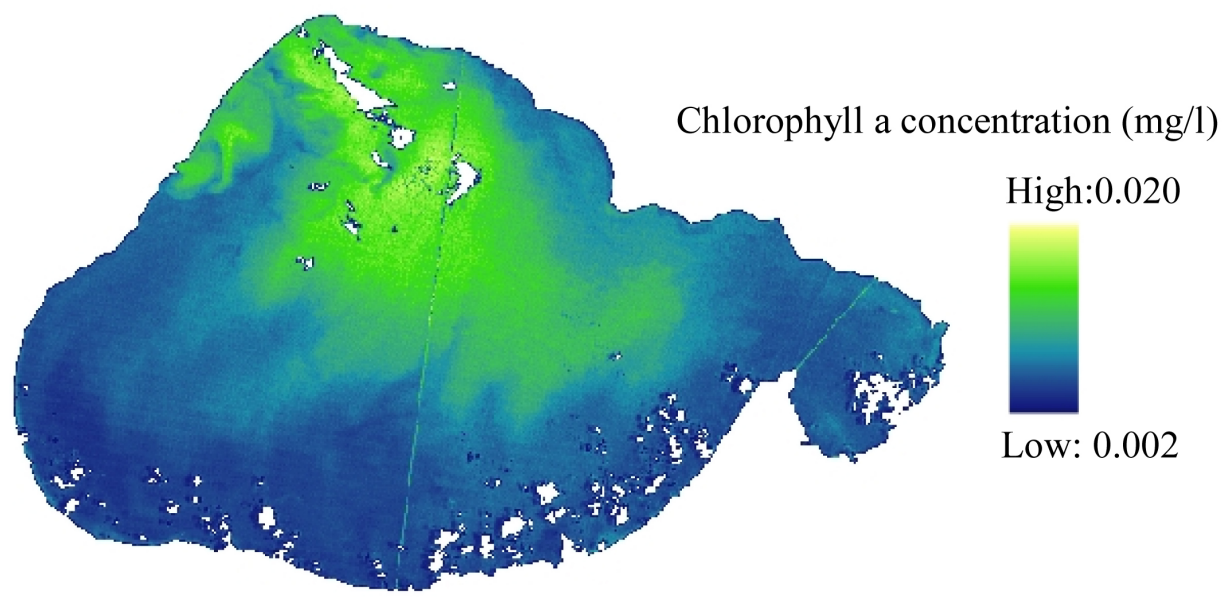

Figure 8. The remote sensing imageries of chlorophyll a concentration in Lake Pontchartrain (May 28, 1997, estimated by Landsat 5 TM imagery).

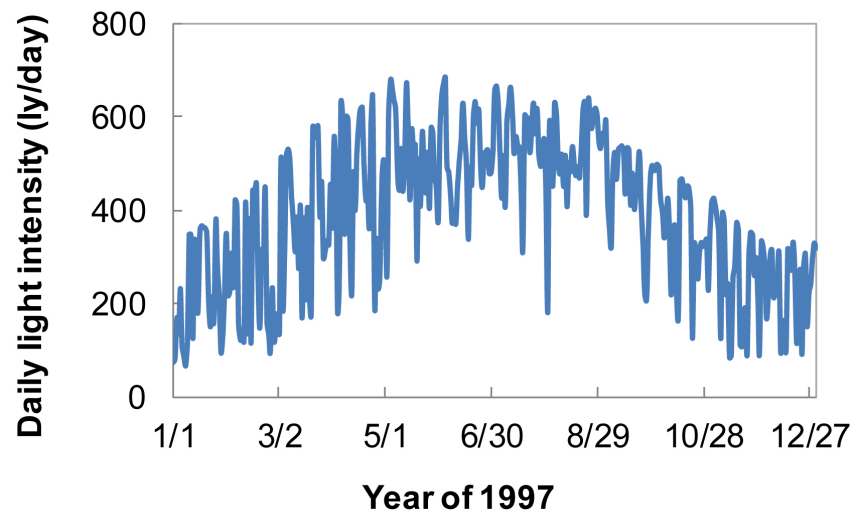

Figure 9. Daily light intensity on the water surface. 
model simulates the chlorophyll concentration, and their relationship can be obtained using Equation (9). Due to the lack of observed algae biomass data (or chlorophyll concentration), the satellite imagery was used for model validation. Figure 11(a) shows the observed algal bloom distribution obtained from remote sensing imagery acquired on June 13, 1997. Figure 11(b) shows the simulated chlorophyll a concentration. The area with higher chlorophyll a concentration might be the potential area for algal blooming. It can be found that the simulated results and satellite imagery show a similar pattern.

\section{Discussion}

\section{The Effect of SS on the Algal Bloom in Lake Pontchartrain during the BCS Flood Release}

When the BCS is opened for flood release, large amount of fresh and cooler water, sediment, nutrients, etc. will discharge into Lake Pontchartrain. As shown in Equation (15), the light attenuation coefficient $K_{e}$ increases due to higher SS concentration. Based on Equations (12) and (14), the light limitation factor $f_{I}$ reduces due to higher light

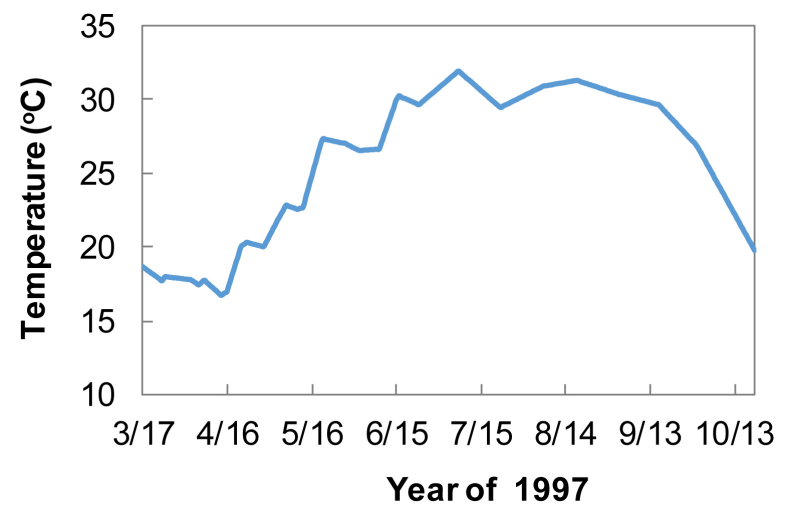

Figure 10. Water temperature of the lake.

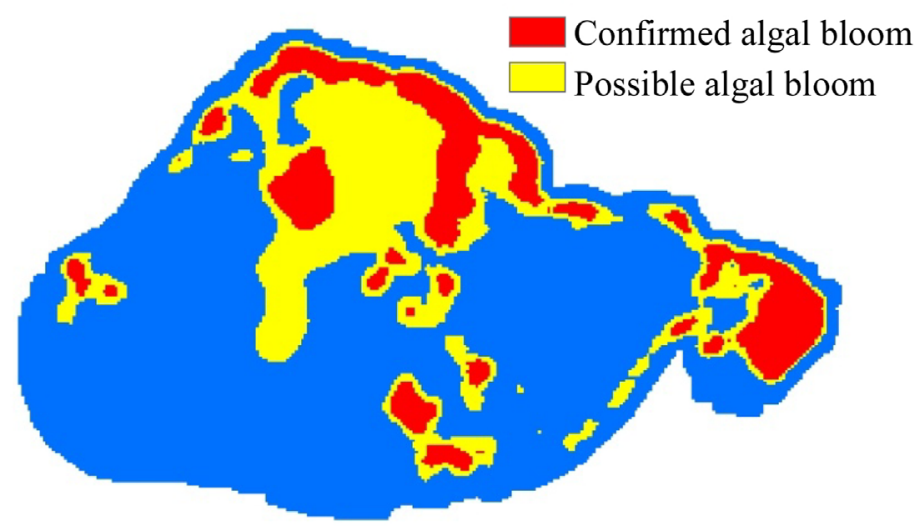

(a)

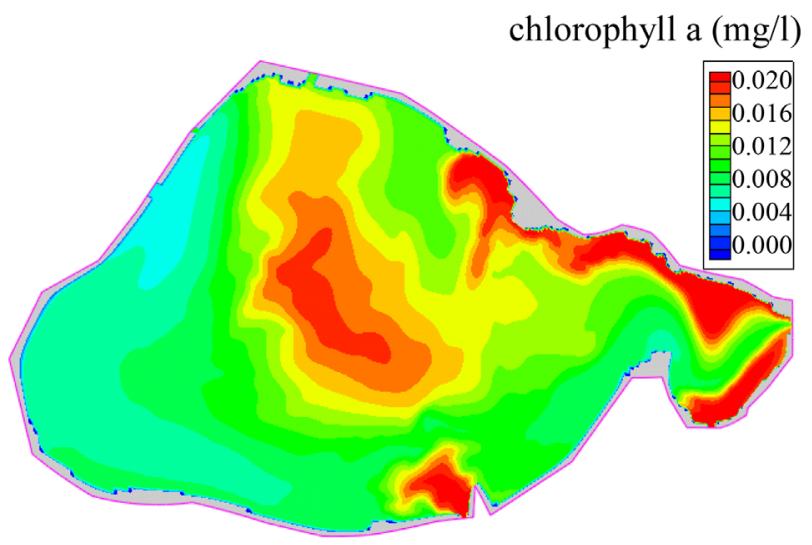

(b)

Figure 11. (a) Mapping probable algal blooms in the Lake (June 13, 1997, estimated by Landsat 5 TM) imagery); (b) Simulated chlorophyll a concentration. 
attenuation coefficient $K_{e}$, and causes the algal growth rate reduces. In general, there is no algal bloom observed during the BCS opening period. The reason could be the algal growth rate is greatly restricted by the high suspended sediment (SS) concentration in the lake.

For 1997 flood release event, the BCS opening period was from March 18 to April 17. Due to the high nutrient level in this period, the nutrient limitation factor $f_{N}$ can reach as high as 1.0. Figure 12 shows the temperature limitation factor $f_{T}$ in this period. The averaged value is about 0.65 , which means the lake temperature is suitable for algae growth. Based on the field observation, the averaged SS concentration in the lake could be as high as $100 \mathrm{mg} / \mathrm{l}$, and the initial chlorophyll concentration was about $0.008 \mathrm{mg} / \mathrm{l}$. Figure 13 shows the light limitation factor $f_{I}$ obtained from Equation (14). In the period of BCS opening, the averaged $f_{I}$ is about 0.037 . In general, such a low light limitation factor indicates that the light in the water is not sufficient for the growth of algae. Under these conditions, the algal growth rate can be estimated using Equation (12). As shown in Figure 14, the averaged algal growth rate is about 0.05 day $^{-1}$, which is lower than the general death rate (around $0.1 \mathrm{day}^{-1}$ ). So there was no algal boom observed during the BCS opening for flood release. As expected, if SS concentration reduces, the algal growth rate will increase.

A sensitivity analysis was conducted to study the growth rate by reducing SS concen-

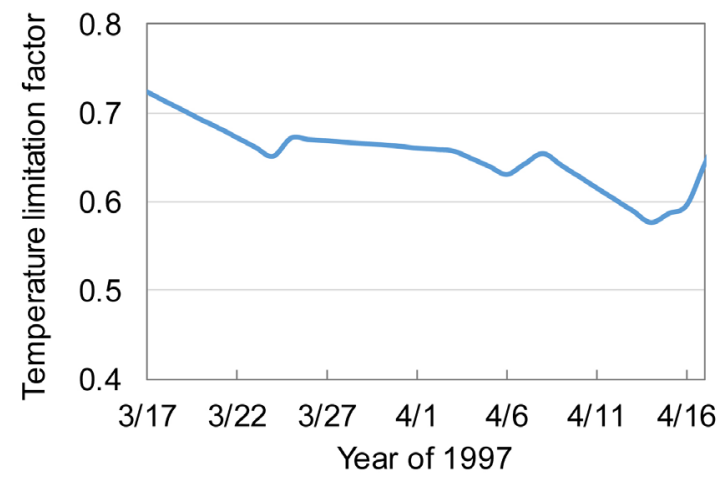

Figure 12. Temperature limitation factor during BCS opening.

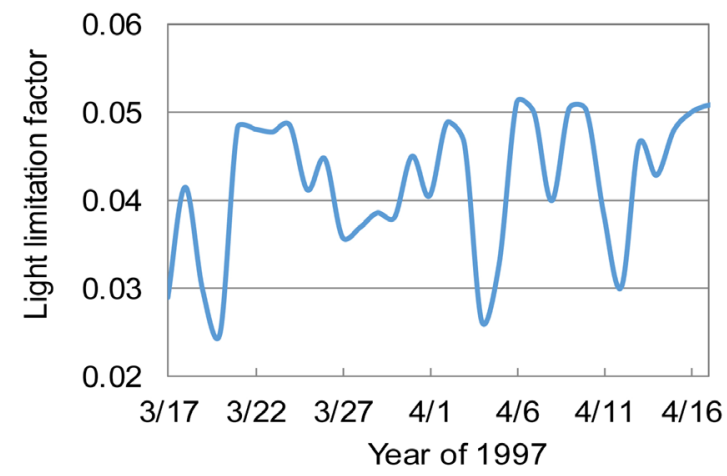

Figure 13. Light limitation factor during BCS opening. 
tration from $100 \mathrm{~kg} / \mathrm{l}$ to $10 \mathrm{~kg} / \mathrm{l}$, and keeping other conditions same. Figure 15 shows the algal growth rate may increase about 3 times when SS concentration reduces from $100 \mathrm{~kg} / \mathrm{l}$ to $10 \mathrm{~kg} / \mathrm{l}$.

\section{Summary and Conclusions}

A 2D numerical model was developed and applied to simulate the wind and tide induced flow fields, sediment transport and algal biomass distribution in Lake Pontchartrain. The model was first calibrated using measured water surface elevation and velocity in Lake Pontchartrain, and then it was applied to simulate the flow fields, sediment transport and algal biomass distributions due to the BCS opening for flood release. The simulated results were generally in good agreement with field observations provided by USGS and satellite imagery obtained from NASA.

In general, during the period of BCS opening, the light attenuation coefficient increases due to the high sediment concentration of the lake. Therefore, the algae growth rate is very low and there is no algal bloom observed.

After the BCS closure, the suspended sediment gradually settles down to the bed, and the light attenuation coefficient decreases. The algal growth rate could increase due to the high nutrient concentration and low sediment concentration. The algal bloom may occur potentially. For 1997 BCS opening event, the field observation data and simulation results showed after one and half month of the BCS closure; the algal bloom started

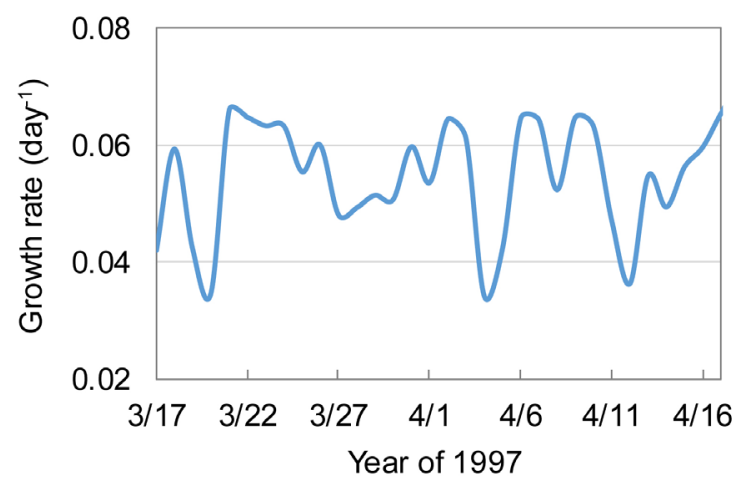

Figure 14. Algal growth rate $(\mathrm{SS}=100 \mathrm{mg} / \mathrm{l})$.

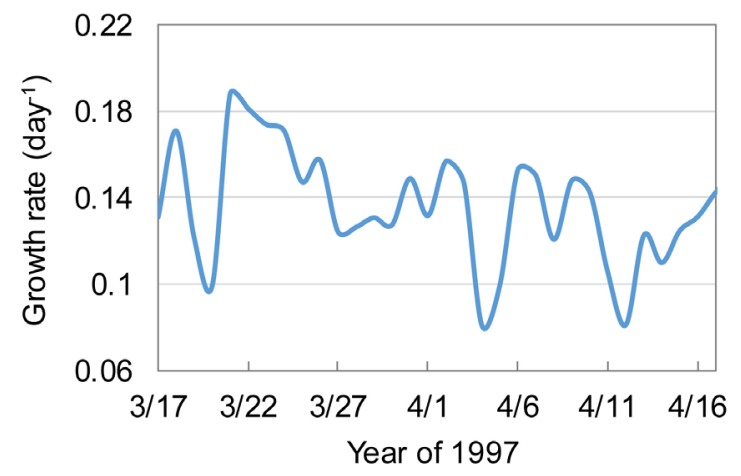

Figure 15. Algal growth rate ( $\mathrm{SS}=10 \mathrm{mg} / \mathrm{l})$. 
to occur at the end of May and last for about one month.

The research has positively demonstrated that the developed model is capable of predicting flow fields, sediment transport and algal biomass distribution in Lake Pontchartrain due to BCS opening for flood release. The model results provide useful information to analyze and evaluate environmental impacts of spillway opening events on the lake.

\section{Acknowledgements}

This research was funded by the US Department of Homeland Security and was sponsored by the Southeast Region Research Initiative (SERRI) at the Department of Energy's Oak Ridge National Laboratory (Contract number: DEAC0500OR22725). The authors would like to thank Rich Signell and David Walters of the USGS, and George Brown of the US Army Corps of Engineers for providing field measured data in Lake Pontchartrain. The technical assistance from Yaoxin Zhang of the University of Mississippi are highly appreciated. This study is also sponsored in part by the USDA-ARS Specific Research Agreement No. 58-6408-7-236 and the University of Mississippi.

\section{References}

[1] Penland, S., Beall, A. and Kindinger, J. (2002) Environmental Atlas of the Lake Pontchartrain Basin, USGS Open File Report 02-206.

[2] Jia, Y., Chao, X., Zhang, Y. and Zhu, T. (2013) Technical Manual of CCHE2D, Version4.1, NCCHE-TR-02-2013.

[3] Smagorinsky, J. (1993) Large Eddy Simulation of Complex Engineering and Geophysical Flows. In: Galperin, B. and Orszag S.A., Eds., Evolution of Physical Oceanography, Cambridge University Press, Cambridge, 3-36.

[4] Jia, Y. and Wang, S.S.Y. (1999) Numerical Model for Channel Flow and Morphological Change Studies. Journal of Hydraulic Engineering, 125, 924-933.

http://dx.doi.org/10.1061/(ASCE)0733-9429(1999)125:9(924)

[5] Jia, Y., Wang, S.Y.Y. and Xu, Y. (2002) Validation and Application of a 2D Model to Channels with Complex Geometry. International Journal of Computational Engineering Science, 3, 57-71. http://dx.doi.org/10.1142/S146587630200054X

[6] Wu, W. (2008) Computational River Dynamics. Taylor \& Francis Group, London.

[7] Koutitas, C. and O'Connor, B. (1980) Modeling Three-Dimensional Wind-Induced Flows. Journal of Hydraulic Engineering, 106, 1843-1865.

[8] Jin, K.R., Hamrick, J.H. and Tisdale, T. (2000) Application of Three Dimensional Hydrodynamic Model for Lake Okeechobee. Journal of Hydraulic Engineering, 126, 758-771. http://dx.doi.org/10.1061/(ASCE)0733-9429(2000)126:10(758)

[9] Huang, W. and Spaulding, M. (1995) 3D Model of Estuarine Circulation and Water Quality Induced by Surface Discharges. Journal of Hydraulic Engineering, 121, 300-311. http://dx.doi.org/10.1061/(ASCE)0733-9429(1995)121:4(300)

[10] Rueda, F.J. and Schladow, S.G. (2003) Dynamics of Large Polymictic Lake. II: Numerical Simulations. Journal of Hydraulic Engineering, 129, 92-101. http://dx.doi.org/10.1061/(ASCE)0733-9429(2003)129:2(92)

[11] Chao, X., Jia, Y. and Shields, D. (2004) Three Dimensional Numerical Simulation of Flow 
and Mass Transport in a Shallow Oxbow Lake. World Water \& Environmental Resources Congress 2004, ASCE, Resyon, CD-Rom.

[12] Cerco, C.F. and Cole, T. (1995) User's Guide to the CE-QUAL-ICM: Three-Dimensional Eutrophication Model. Technical Report EL-95-1 5, U.S. Army Corps of Engineers, Vicksburg, MS.

[13] Wool, T.M., et al. (2001) Water Quality Analysis Simulation Program (WASP) Version 6. User's Manual, US Environmental Protection Agency, Atlanta, GA.

[14] Chapra, S.C. (1997) Surface Water-Quality Modeling. The Mcgraw-Hill Companies, Inc, New York.

[15] Chao, X., Jia, Y., Shields, D. and Wang, S.S.Y. (2007) Numerical Modeling of Water Quality and Sediment Related Processes. Ecological Modelling, 201, 385-397.

http://dx.doi.org/10.1016/j.ecolmodel.2006.10.003

[16] Zhang, Y. and Jia, Y. (2009) CCHE Mesh Generator and User's Manual. Technical Report No. NCCHE-TR-2009-1, University of Mississippi.

[17] Dortch, Q., Peterson, J. and Turner, R. (1998) Algal Bloom Resulting from the Opening of the Bonnet Carre Spillway in 1997. Fourth Bi-Annual Basics of the Basin Symposium. United States Geological Survey, 28-29.

[18] McCorquodale, J.A., Georgiou, I. and Chilmakuri, C. (2004) Application of a 3-D Model to Assessing the Risk of an Algal Bloom. The 6 th International Conference on Hydroscience and Engineering, Brisbane, 30 May-3 June 2004, CD-Rom.

\section{Submit or recommend next manuscript to SCIRP and we will provide best service} for you:

Accepting pre-submission inquiries through Email, Facebook, LinkedIn, Twitter, etc. A wide selection of journals (inclusive of 9 subjects, more than 200 journals)

Providing 24-hour high-quality service

User-friendly online submission system

Fair and swift peer-review system

Efficient typesetting and proofreading procedure

Display of the result of downloads and visits, as well as the number of cited articles

Maximum dissemination of your research work

Submit your manuscript at: http://papersubmission.scirp.org/

Or contact gep@scirp.org 